\section{CONGENITAL PYLORIC OBSTRUCTION}

I. Etiology: An Experimental Study

JESSIE LAIRD BRODIE ${ }^{1}$

From the Collins Laboratory of Nutritional Research, University of Oregon Medical School

Received for publication December 6, 1928

For a period of more than three years the Collins Laboratory in Nutritional Research has been investigating the problem of the effect upon the young of inadequate maternal diets during pregnancy and lactation, with special reference to inadequacy in the antineuritic vitamin. The tendency toward polyneuritis and hemorrhage has been detailed elsewhere (1) and in the present paper it is purposed to present a description of ten young which were born and nursed by mothers on a minimal vitamin $B$ containing diet, and which presented a condition simulating that known in man as "congenital hypertrophic pyloric stenosis."

Osborne and Mendel (2) found in 1922 that $200 \mathrm{mgm}$. (or in our diets 2 per cent) of brewer's yeast was sufficient for the growth and reproduction of an albino rat. More recent investigations (3) tend to show that a female on this amount of the $B$ factor cannot wean the majority of her young. They die during the nursing period with symptoms of polyneuritis, although the mother shows neither the characteristic clinical picture nor the autopsy findings of this disease.

The earliest manifestation of the deficiency in the young is the occurrence of hemorrhages in the skin, bones, muscles, brain, or other viscera with death of from 25 to 50 per cent of those in the litter (1), (3, B. Sure) (table 1). Then, as summarized in table 2 , there may appear during the second week the condition which we have placed under the general term pyloric obstruction. A few of the young of the first generation and almost one-fourth of the young of the second generation develop marked emaciation, combined with a rapidly enlarging abdomen of extremely firm consistency. These animals, being rodents, cannot vomit. At autopsy, when the abdominal

1 Presented to the Department of Surgery, May 15, 1928, in partial fulfilment of the degree of Doctor of Medicine, University of Oregon Medical School.

Appreciation is gratefully acknowledged to C. Ulysses Moore, Robert B. Hope, and Olaf Larsell for suggestions and technical assistance.

Read by invitation before the North Pacific Pediatric Society at Vancouver, B. C. June 28, 1928. wall was slit, the stomach popped out as though under pressure. It was distended to at least three times its normal size by tightly packed curd which, on splitting the stomach wall, rolled out in a complete cast of the mucosa. It held its form perfectly until torn apart. The pylorus was tightly constricted, but patent to the extent that a small probe could be passed, although with difficulty. In some of the animals the pylorus appeared grossly hypertrophic. In every case in which the vagi were obtained and stained with osmic acid myelin degeneration was found. Several times hemorrhages were demonstrable in the muscles, abdominal viscera or brain

Practically all of the young who live to the third week show clinically a marked paralysis, especially of the hind quarters, profuse watery stools and a subnormal temperature. The few who are strong enough to eat from the mother's ration or who are fed concentrated vitamin $B$ by pipette,

TABLE 1

\begin{tabular}{|c|c|c|c|c|c|c|c|c|c|}
\hline GENBRATION & 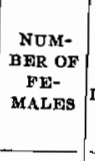 & \begin{tabular}{|} 
NUM- \\
PER OF \\
LITTERS
\end{tabular} & $\begin{array}{c}\text { NDMM } \\
\text { BRR OF } \\
\text { YOUNG } \\
\end{array}$ & 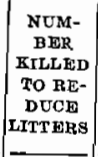 & 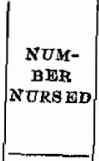 & 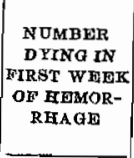 & 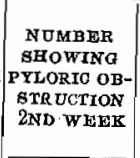 & 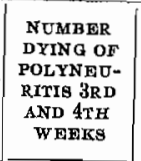 & $\begin{array}{l}\text { NDMBER } \\
\text { WEANED }\end{array}$ \\
\hline $\begin{array}{l}\text { First.... } \\
\text { Second.. }\end{array}$ & $\begin{array}{r}19 \\
5\end{array}$ & $\begin{array}{r}33 \\
6\end{array}$ & $\begin{array}{r}198 \\
43\end{array}$ & $\begin{array}{r}28 \\
7\end{array}$ & $\begin{array}{r}170 \\
36\end{array}$ & $\begin{array}{r}76(45 \%) \\
8(22 \%)\end{array}$ & $\left|\begin{array}{l}2(1.2 \%) \\
8(22 \%)\end{array}\right|$ & $\left|\begin{array}{ll}63 & (38 \%) \\
21 & (58 \%)\end{array}\right|$ & $\begin{array}{r}32(18 \%) \\
2(5.5 \%)\end{array}$ \\
\hline
\end{tabular}

Maternal diet: Basal I, containing 2 per cent desiccated yeast.

Hemorrhage, pyloric obstruetion, and polyneuritis form the outstanding pathology in the fist, second, and third weeks, respectively Some animing pathpyloric obstruction and later, polyneuritis.

usually make an uneventful recovery (1), (3, B. Sure). The majority, however, die. Autopsy is grossly negative except for occasional macroscopic visceral, subcutaneous, or intramuscular hemorrhages. Microscopically, however, the sciatic and other myelinated nerves show, when properly stained, degeneration of the myelin sheath.

With this complete history in mind, and noting that 65 to 90 per cent of those living to three weeks of age died from frank polyneuritis, cent of vitamin B deficiency disease, it does not seem inconsistent to consider the pyloric obstruction as merely another manifestation of the general deficiency of this vitamin. It is only upon the basal I diet $t^{2}$ which is minimal in this factor that the condition has been found at all. Other diets identical, so far as we can tell, in all respects save for a larger amount of 2 Basal I diet: 18 per cent crsein, 3 per cent crisco, 2 per cent cod liver oil, 4 per cent salt mixture, (no. $185 \mathrm{McC}$ ollum), 71 per cent dextrin, and 2 per cent jeast (powdered yeast foam tablets of the North per cent dextrin, and 2 per cent yeast 


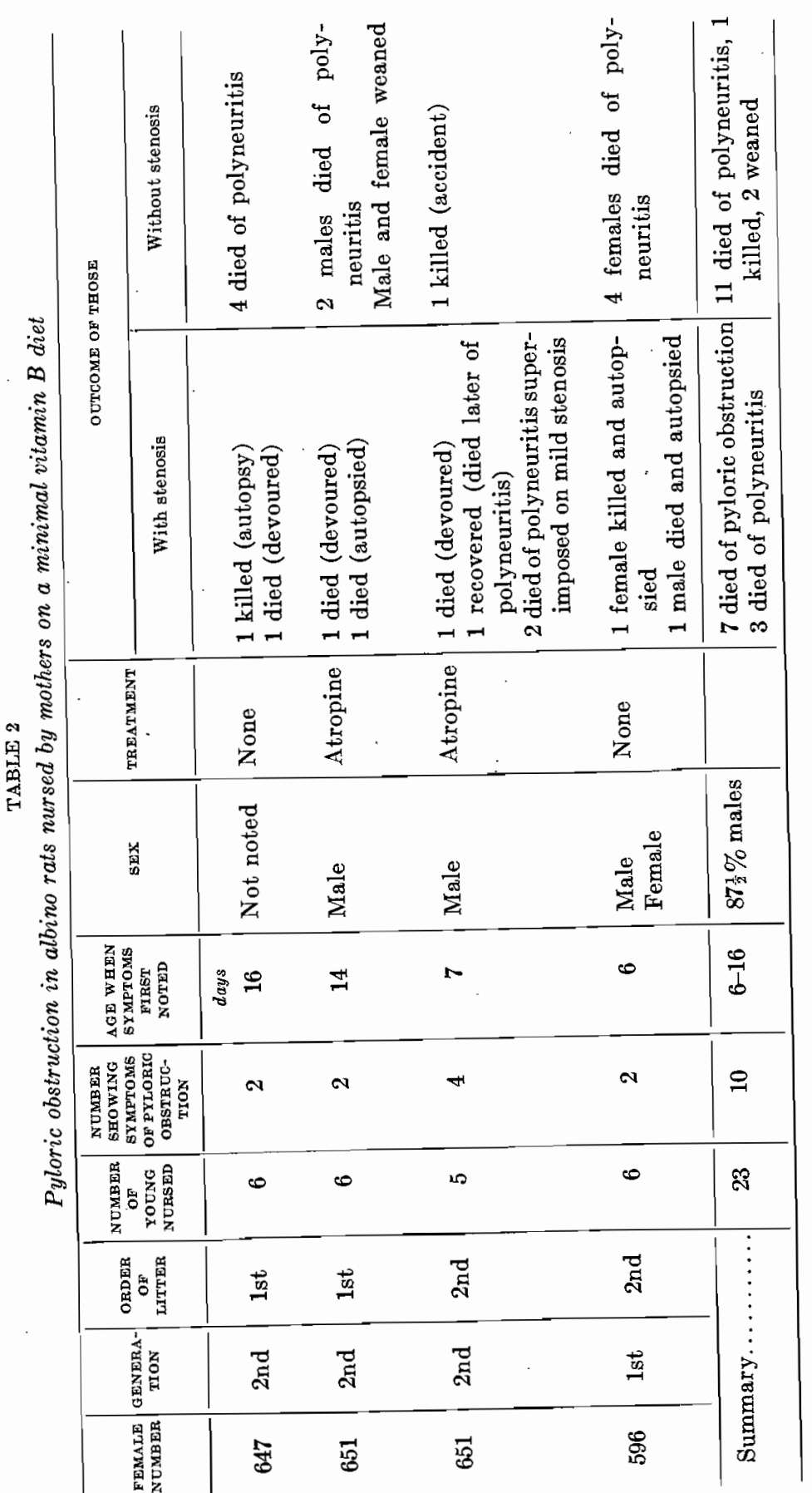

yeast, have never shown a single case of pyloric obstruction, nor have any of the hundreds of the litters on the stock diet.

Moreover it is interesting to note that pyloric obstruction developed in only 1.2 per cent of the young of the first generation raised on this diet restricted in vitamin $B$, while 22 per cent of the young of the second generation have shown the condition. It has long been known that vitamin $B$ is not stored for any length of time in the animal organism (4) and when fed at a level minimal for growth any slight store would soon be depleted. The first generation is taken from the stock diet at the age of four to six weeks and their young show at least the terminal paralysis. The second generation never receive more than 2 per cent yeast, and when their young are born the deficiency must be extremely marked and begins to show earlier in the process of myelinogeny, e.g., when the vagi are being myelinated. If these escape sufficiently the peripheral nerves are the first to give indication of the disease. When two of the young with mild pyloric obstruction lived untreated to the age when myelination of the sciatics should have been completed the typical picture of polyneuritis was superimposed upon the primary condition.

One of the young of the first litter of female 651 (table 2) was given a dose of atropine sulphate comparable to that used for human babies but with entirely negative results. As this treatment was unsuccessful, the susceptibility of these animals to atropine was investigated both experimentally on normal animals and by consulting the literature. Sollmann (5) suggests that rats are very resistant to this drug, taking at least 2.5 grams per kilo as the minimal fatal dose. Our experimental findings showed an even greater resistance. In the later cases of pyloric obstruction, therefore, two of the males were given subcutaneous injections of 0.2 cc. of 0.1 per cent atropine sulphate for two consecutive days. The animal that had shown the most marked distention died and was devoured on the second day. The other male showed a very soft stomach so the dose was reduced to $0.1 \mathrm{cc}$ on the third day and then discontinued. In a few days he developed a marked diarrhea and paralysis and died of polyneuritis.

Many of our attempts to secure the vagus in these animals were unsuccessful. In the first cases we did not realize the significance of obtaining this nerve; in many of the later ones the mother devoured at least a large portion of the body; and in a few animals the specimens dissected from. these five-gram animals showed themselves to be blood vessels or other tissues when we thought we had the thread-like vagus. Older animals, three to four weeks, nursed by mothers on this same diet and dying with symptoms of polyneuritis practically always showed some degeneration of the vagus, although never to the marked extent of that found in the sciatic. In these cases the only symptoms referable to the gastro-intestinal 
tract were loss of appetite and a terminal diarrhea, and at autopsy gaseous distention and atony of the bowel. When pyloric obstruction was most marked (young of female 596) there was an extensive degeneration of the vagus comparable to the extreme gastro-intestinal symptoms. Further work along this line is certainly needed before the exact relationship of the degeneration of the vagus to the pyloric obstruction is ascertained.

Studies of the literature show us also a dearth of knowledge on three other questions intimately associated with this problem: 1 , the function of the myelin sheath; 2 , the significance of myelin degeneration in the clinical picture of vitamin B deficiency; and 3, the nervous control of the pyloric sphincter.

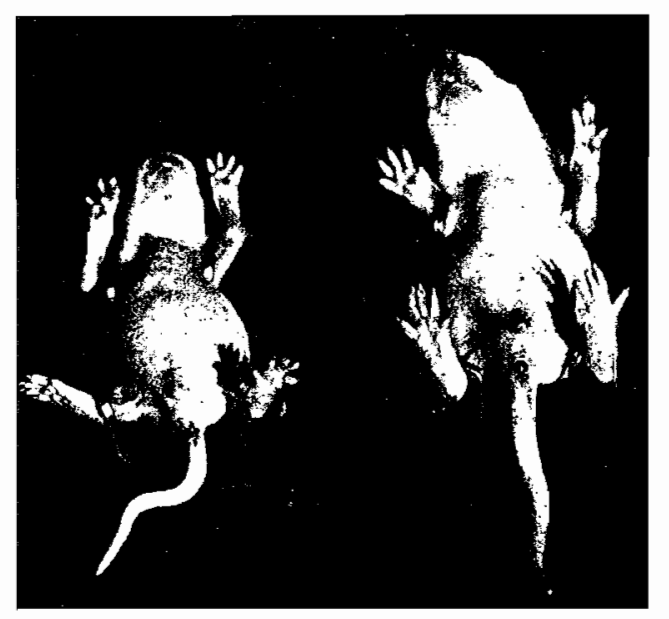

Fig. 1. Litter mates from mother on minimal $B$ diet. Animal on left shows emaciation, stunting of growth, and distention of the abdomen. At autopsy the latter was found due to gastric dilatation secondary to pyloric obstruction. The brother on the right has normal growth and average abdominal size.

The myelin sheath is believed (6) to serve the function either of insulation or nutrition to the nerve, and consequently a disease affecting this material may have two stages, an early period in which there is irritability and a later one where the nerve is entirely non-functional. Clinically beri-beri shows these two stages.

Work is now being carried on in this laboratory to find out if possible how a deficiency of the anti-neuritic vitamin affects myelinogeny or nerve development in general. Babies show a vitamin $\mathbf{B}$ deficiency on diets minimal in this factor when their mothers show no symptoms of the disease. Is it due to a high mammary threshold for the anti-neuritic factor, or does the developing nervous system require a larger amount of this "metabolic building stone" (7)? The vagus is not fully formed at the time of birth in any species, but varies from practically no myelin formation in the rat (8) to a very small number of myelinated fibers in the higher species of mammals (9). Myelination takes place very rapidly after birth. Many workers on this subject hold that myelin degeneration is merely the indicator of a more extensive process taking place in the nerve cells proper Vedder (7) claims that the antineuritic vitamin is a building stone which is essential for the normal metabolism of nervous tissue. "A certain amount of this vitamin is constantly necessary in order to maintain the nervous system in healthy condition. If the supply of vitamin is cut down by any dietary that contains an insufficient amount of this substance the normal metabolism of the nervous system at once suffers. If the faulty diet is continued, degeneration of the nervous system progresses steadily until a point is reached at which the symptoms of beri-beri appear." Ellis (10) finds from his more complete histological studies that the sympathetic unmyelinated fibers are also widely involved.

The nervous control of the pyloric sphincter cannot be divided as can that of other parts of the gastro-intestinal tract into sympathetics and parasympathetics that are directly antagonistic (11). Both the splanchnics and vagi of this region are mainly motor in function, although containing inhibitor as well as motor fibers. The tonus of the musculature determines the end result of the stimulus (12).

Some of the recent work (13) indicates that in pyloric obstruction we have overstimulation of the motor nerves, while others seem to show (14) that lack of stimulation causes contraction rings. Much more work must be done before a definite conclusion can be reached as to whether the pyloric obstruction is due to an early degeneration of the vagus resulting in overstimulation of the pyloric antrum or perhaps lack of stimulation over the parasympathetics in the late stages resulting in contraction rings. Against this latter theory, however, are the well known beneficial results in pylorospasm of babies from the use of atropine, which paralyzes the parasympathetic nerve endings.

It may be difficult to see how a comparison can be made between a condition in rats in which the stomach becomes markedly distended with food and one in human babies in which food can not be retained in the stomach. But we must bear in mind the fact that we are dealing in the first instance with rodents, animals that are incapable of vomiting (15). As this repeated taking of food into the stomach continues, with little or no discharge through the pylorus, the strenuous action of the pyloric antrum results in a firm packing of the milk curd into the cast found at autopsy. In the human baby the strenuous and ineffectual peristalsis produces a marked projectile type of vomiting.

It has been found, in this and other laboratories where experiments on 
the production of polyneuritis in young animals are going on, that on the whole the males fall sick earlier than the females and show a more severe form of the disease. In Japan, the Philippines and other countries where it is so prevalent, beri-beri is reported to attack males much oftener than females (16). In our experimental cases of pyloric obstruction the sex of one litter was not recorded, but out of the other eight animals showing the condition seven or 87.5 per cent were males (table 2). Clinical reports of congenital hypertrophic pyloric stenosis all agree that a preponderance of cases is found among boy babies. Many authors mention as high as 90 per cent incidence in males with a mortality two or three times that of females (17).

It is unnecessary to go into detail at this time in regard to existing theories concerning etiology (18). The arguments have waged for years as to whether the hypertrophy preceded the spasm or the spasm caused the hypertrophy, but all attempts at proof both experimentally and clinically have ended unsuccessfully, so far as we have been able to ascertain. In respect to the tumor formation our experiments are also inconclusive. The stomachs of the young rats were so distended and stretched with food that it was difficult to make a satisfactory comparison, although we felt that in many cases a gross hypertrophy could be made out. Sections were not satisfactory, for we found, in agreement with Hertz, Mohr, Aschoff, Pfaundler (19) and others, that the plane of section, hardening fluids, size of sections and stage of contraction all must be taken into consideration.

Thomson (20) and Haas (21) have been strongest in the support of the theory that hypertrophic pyloric stenosis is merely an advanced degree of pylorospasm due to a functional disturbance of the nerves of the stomach and pylorus leading to ill coördinated and therefore antagonistic action. But no one has presented a reason for this "disturbance of the physiological function of the vegetative nervous system." In the experimental work presented above the condition was associated with a minimal amount of the anti-neuritic vitamin.

Some very interesting and conclusive work has recently been published by Macy and associates (22) from the Nutritional Research Laboratories of the Merrill-Palmer School and Children's Hospital of Michigan. They find that the antineuritic potency of the mixed milk of a group of wet nurses receiving the average American dietary is very slight. "In view of the facts presented, it is possible that many mothers do not supply enough of vitamin B to their babies."

Much more work is necessary along the line of both the experimental production of the disease in animals and the checking of maternal dietary histories where the disease occurs in humans. Only when this is coupled with numerous autopsy reports of babies dying of pyloric stenosis, including a study of nerves, can we reach a definite decision as to the probability of a vitamin deficiency as the basis of certain cases of human pyloric obstruction.
SUMMARY

1. Protocols are presented of four litters of albino rats in which ten out of twenty-three young showed pyloric obstruction. The diet of the mother was minimal in the anti-neuritic vitamin.

2. The clinical picture presented was an enlarged and very firm abdomen with extreme general emaciation. At autopsy the stomach was found enlarged and packed with curd, and the vagus in all cases examined showed myelin degeneration.

3. In the cases in which the condition was mild or cured by atropine, polyneuritis was later superimposed upon the original condition. The pyloric obstruction is therefore considered as one manifestation of vitamin B deficiency with resulting defective myelinogeny.

4. One and two-tenths per cent of the young of the first generation showed this condition, and twenty-two per cent of the young of the second generation.

5. Eighty-seven and a half per cent of the young thus affected were males.

6. Comparison is made between this condition in rodents, who cannot vomit, and human babies with congenital pyloric stenosis. The age of onset, sex, and response to atropine all point to a similarity between the two conditions.

\section{BIBLIOGRAPHY}

(1) Moore, C. U., J. L. Brodie and R. B. Hope. 1927. This Journal, lxxxii, 350. Moore, C. U. aNd J. L. Brodre. 1927. Amer. Journ. Dis. Child., xxxiv, 53. Manvilue, I. A., J. L. Brodie and C. U. Moore. 1926. Northwest Med. $\mathrm{xxv}, 205$.

(2) Osborne, R. B. and L. B. Mendez. 1922. Journ. Biol. Chem., liv, 739.

(3) AnderegG, L. T. 1924. Journ. Biol. Chem., lix, 587.

Evans, H. M. ANd H. S. Burr. 1928. Journ. Bỉol. Chem., lxxvi, 263.

Grant, A. H. 1924. Univ. Cincinnati Med. Bull., iii, 17.

Hartweld, G. A. 1921. Biochem. Journ., xv, 140, 563; 1925, Ibid., xix, 1075 HeLLer, V. G. 1923. Journ. Biol. Chem., lv, 385.

Hogan, G. A. and H. M. Harshaw. 1924. Journ. Met. Res., v, 3

Manville, I. A. 1926. Science, lxiv, 256.

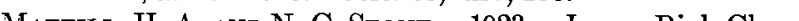

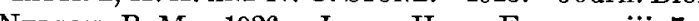

Nexson, P. M. 1926. Journ. Home Econ., xviii, 7.

alson, V. E., R. L. Jones, V. G. Heller, T. B. Parks and E. I. Fulmer. 1926. This Journal, lxxvi, 325 .

Sure, B. 1927. Journ. Amer. Med. Assoc., Ixxxix, 675; Journ. Biol. Chem. lxxiv, 55; Proc. Amer. Soc. Biol. Chem., Idem., lxxiv, 681.

Sure, B. and S. J. Schilding. 1928. Amer. Journ. Dis. Child., xxxv, 811 (4) Steenbock, H., M. T. Sell and J. H. Jones. 1923. Journ. Biol. Chem., Iv 411

(5) SoldmanN, T. 1917. W. B. Saunders Co. Appendix H, p. 323.

(6) Starling, E. H. 1926. Philadelphia, Lea \& Febiger. 
(7) VedDeR, E. B. 1913. Wood \& Co., N. Y. Vedder, E. B. and F. Clark. 1921. Philippine Journ. Sci., vii.

(8) Cornwall, I. H. and R. M. Brickner. 1928. Unpublished data. Connwall, L. H. 1927. Arch. Neurol. and Psychiat., xviii, 240.

(9) Feldman, W. M. 1920. Jongmans, Green \& Co., London.

(10) Elutis, W. G. 1898. Lancet, ii, 985.

(11) Chase, M. R. 1916. Journ. Comp. Neurol., xxvi, 421. HAMMETT, F. S. 1921. This Journal, 1v, 414.

McCrea, E. D. and B. A. McSwiney. 1926. Journ. Physiol., 1xi, 28.

Thomas, J. E. And A. Kuntz. 1926. This Journal, Ixxvi, 598.

(12) McCrea, E. D., B. A. McSwiney and J. S. B. STopford. 1925. Quart. Journ. Exper. Physiol., xv, 200.

(13) Carlson, A. J. and S. Litr. 1924. ·Arch. Int. Med., xxxiii, 281. MoCreia, E. D., B. A. McSwiney and J. S. B. Stopford. 1926. Quart. Journ. Exper. Physiol., xvi, 195.

Thomas, J. E. and H. Wheelon. 1922. Journ, Lab. and Clin. Med., vii, 7.

(14) Alvarez, W. C. 1928. Paul B. Hoeber.

Cannon, W. A. 1908. This Journal, xviii, 429.

(15) Hatchen, R. A. ANd S. Weiss. 1922. Arch. Int. Med, xxix, 690.

Hatcher, R. A. 1924. Physiol. Rev., iv, 479.

(16) Takano, R. 1926. Japan Med. World, vi, 8.

(17) Aldxander, E. G. 1924. Med. Clinics of N. A., viii, 838.

Richter, H. M. Abt's Pediatrics, iii, 452.

Davison, W. C. 1925. Bull. Johns Hopkins Hosp., xxxvii, 75.

Goldbloom, A. 1920. Amer. Journ. Dis. Child., xix, 263.

Heusch, K. 1922. Zeitschr. f. Kinderh., xxxi, 158.

(18) Sauen, L. W. 1924. Arch. Ped., xli, 145.

Moonw, H. L. 1924. South. Med. Journ., xvii, 187.

Davis, H. H. 1924. Journ. Amer. Med. Assoc., Ixxxiii, 686.

Birberback, J. B. 1928. Northwest Med., xxvii, 182.

(19) Aschoff, L. 1919. Jena. "Pathologische Anatomie", 788.

Hertz. 1916. Jahrb. f. Kinderh., 1xxxii, 32, 131.

Morr, M. 1921. Zeitschr. f. Kinderh., xxii, iii.

Pfatndegr, M. 1909. Jahrb. f. Kinderh., lxx, 253.

(20) Thomson, J. 1896. Edinb. Hosp. Re. Edinb. and Lon. iv, 16.

(21) HaAs, S. V. 1918. Amer. Journ. Dis. Child., xv, 323; 1919. Arch. Ped., xxxvi, 516; 1922. Journ. Amer. Med. Assoc., 1xxix, 1314.

(22) Macy, I. C., J. Outhouse, A. Grahili and M. L. Long. 1927. Journ. Biol. Chem., Ixxiii, 189. 